\title{
Do Alterations in Mitochondrial DNA Play a Role in Breast Carcinogenesis?
}

\author{
Thomas E. Rohan, ${ }^{1}$ Lee-Jun Wong, ${ }^{2}$ Tao Wang, ${ }^{1}$ Jonathan Haines, ${ }^{3}$ and Geoffrey C. Kabat ${ }^{1}$ \\ ${ }^{1}$ Department of Epidemiology and Population Health, Albert Einstein College of Medicine, 1300 Morris Park Avenue, Bronx, \\ NY 10461, USA \\ ${ }^{2}$ Department of Molecular and Human Genetics, Baylor College of Medicine, One Baylor Plaza, Houston, TX 77030, USA \\ ${ }^{3}$ Department of Molecular Physiology \& Biophysics, Vanderbilt University Medical Center, 519 Light Hall, Nashville, \\ TN 37232-0700, USA
}

Correspondence should be addressed to Thomas E. Rohan, thomas.rohan@einstein.yu.edu

Received 21 January 2010; Accepted 1 March 2010

Academic Editor: Jean F. Simpson

Copyright (C) 2010 Thomas E. Rohan et al. This is an open access article distributed under the Creative Commons Attribution License, which permits unrestricted use, distribution, and reproduction in any medium, provided the original work is properly cited.

\begin{abstract}
A considerable body of evidence supports a role for oxidative stress in breast carcinogenesis. Due to their role in producing energy via oxidative phosphorylation, the mitochondria are a major source of production of reactive oxygen species, which may damage DNA. The mitochondrial genome may be particularly susceptible to oxidative damage leading to mitochondrial dysfunction. Genetic variants in mtDNA and nuclear DNA may also contribute to mitochondrial dysfunction. In this review, we address the role of alterations in mtDNA in the etiology of breast cancer. Several studies have shown a relatively high frequency of mtDNA mutations in breast tumor tissue in comparison with mutations in normal breast tissue. To date, several studies have examined the association of genetic variants in mtDNA and breast cancer risk. The G10398A mtDNA polymorphism has received the most attention and has been shown to be associated with increased risk in some studies. Other variants have generally been examined in only one or two studies. Genome-wide association studies may help identify new mtDNA variants which modify breast cancer risk. In addition to assessing the main effects of specific variants, gene-gene and gene-environment interactions are likely to explain a greater proportion of the variability in breast cancer risk.
\end{abstract}

\section{Introduction}

Breast cancer has a complex, multifactorial etiology, with contributions from both genetic and environmental factors. Although its etiology is incompletely understood, it has been estimated from studies of twins that hereditary factors explain about $27 \%$ of the variation in breast cancer risk, with the remainder being due to nonshared environmental and lifestyle factors [1]. Factors that have been associated with increased risk include increasing age, a history of breast cancer in a first-degree relative $[2,3]$, a history of benign breast disease $[4,5]$, menstrual and reproductive factors [6$8]$, use of hormone therapy $[9,10]$, a relatively high body mass index (BMI) (in postmenopausal women) [11], alcohol consumption [12], and possibly cigarette consumption [13], while physical activity has been associated with reduced breast cancer risk [14]. Dietary factors (e.g., a relatively high fat intake and relatively low fruit and vegetable intake) have also been postulated to play a role in the etiology of breast cancer [15-17], although the epidemiologic evidence for this is not consistent. Collectively, the generally accepted risk factors for breast cancer explain perhaps $40 \%$ of the variation in breast cancer incidence [18].

There is now a considerable body of evidence to support a role for oxidative stress in carcinogenesis [19]. Oxidative stress is a disturbance in the balance between the production of reactive species (RS) (including reactive oxygen species (ROS)) and antioxidant defenses, resulting in a relative excess of RS [19-21]. RS are unstable and can react with and damage nuclear and mitochondrial DNA [22]. Additionally, they may alter the expression of genes that stimulate cell proliferation and differentiation [22, 23], and cause lipid peroxidation, protein modification, and membrane disruption [18]. 
Due to their role in producing energy via oxidative phosphorylation, the mitochondria are a major source of production of reactive oxygen species (ROS) [24, 25]. Furthermore, mitochondrial DNA (mtDNA) may be particularly vulnerable to oxidative damage because they lack protective histones and the efficient DNA repair mechanisms present in the nucleus $[24,26,27]$. Indeed, the mutation rate of mtDNA has been reported to be 10-200 times that of nuclear DNA [28-30]. Damage to mtDNA due to ROS may provide (at least in part) a mechanistic explanation for the association with breast cancer of many of the risk factors described above [18]. For example, risk of breast cancer related to reproductive and hormonal factors could be due to the metabolism of estradiol to reactive hydroxy radicals through redox cycling of the catechol estrogens $[18,31]$, while alcohol metabolism might also result in the generation of ROS [32].

A possible role of the mitochondria in cancer was first postulated by Warburg 70 years ago [33], and most research has focused on somatic mutations in mtDNA [34, 35]. Recently, however, a number of studies have addressed the possibility that mitochondrial DNA variants may also play a role in the etiology of specific cancers $[24,35,36]$. In this review, we summarize what is known about the role of oxidative stress in relation to cancer generally and to breast cancer in particular, how exogenous and endogenous exposures might contribute to oxidative stress, the function of the mitochondrion and the mitochondrial genome, and the possible role of mtDNA mutations and polymorphisms in breast carcinogenesis. Finally, we discuss specific topics for future research.

\section{The Mitochondrion}

Mitochondria are the energy-transducing organelles of eukaryotic cells in which fuels that drive cellular metabolism (e.g., carbohydrates and fats) are converted into adenosine triphosphate (ATP) through the electron transport chain and the oxidative phosphorylation system (the "respiratory chain") $[37,38]$. They are also involved in calcium buffering and the regulation of apoptosis [39]. They arose as intracellular symbionts in the evolutionary past, and can be traced to the prokaryote $\alpha$-proteobacterium [40]. There are hundreds to thousands of mitochondria per cell [37].

Structurally, mitochondria have four compartments: the outer membrane, the inner membrane, the intermembrane space, and the matrix (the region inside the inner membrane) (Figure 1) [37, 41]. The respiratory chain is located in the inner mitochondrial membrane. It consists of five multimeric protein complexes: reduced nicotinamide adenine dinucleotide (NADH) dehydrogenase-ubiquinone oxidoreductase (complex I), succinate dehydrogenase-ubiquinone oxidoreductase (complex II), ubiquinone-cytochrome c oxidoreductase (complex III), cytochrome c oxidase (complex IV), and ATP synthase (complex V). In addition, the respiratory chain requires 2 small electron carriers, ubiquinone and cytochrome c.

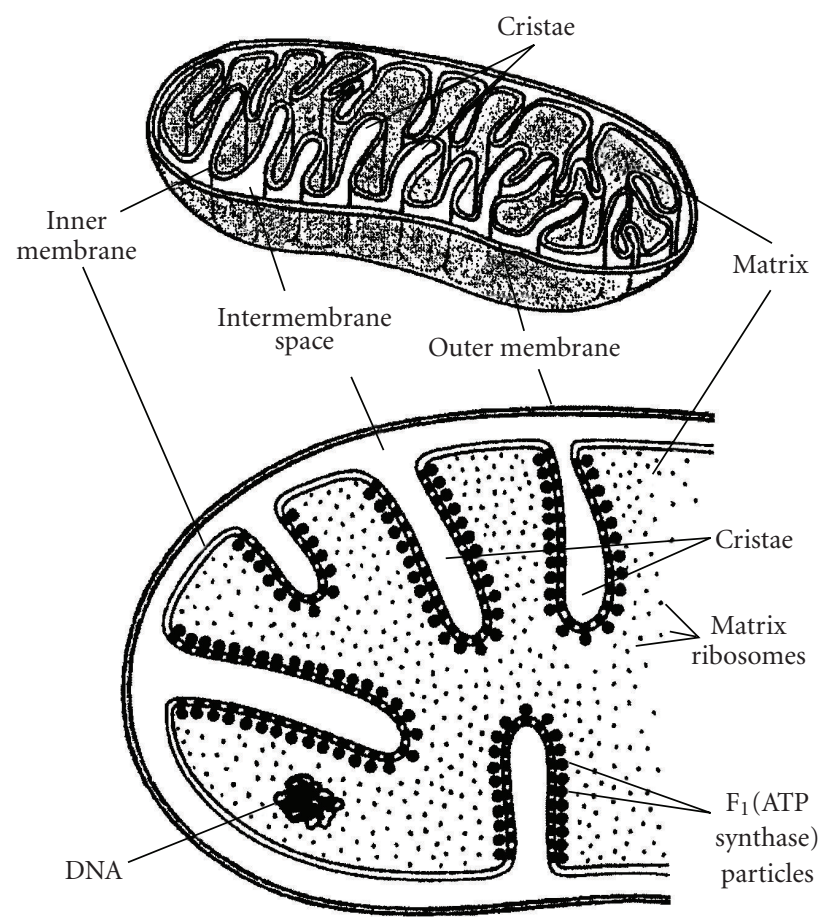

FIGURE 1: Mitochondrial structure adapted by Freitas [41] (Reproduced with permission from Freitas Nanomedicine, Volume I: Basic Capabilities. Austin: Landes Bioscience, 1999:264), Vander et al. (Reproduced with permission of The McGraw-Hill Companies) [42], and Becker, Deamer (Used by permission of Pearson Education, Inc.) [43].

Energy generation via ATP synthesis involves two coordinated processes [37]: electrons (hydrogen ions derived from $\mathrm{NADH}$ and reduced flavin adenine dinucleotide) are transported along the complexes to molecular oxygen, resulting in the production of water; simultaneously, protons are pumped across the mitochondrial inner membrane (from the matrix to the intermembrane space) by complexes I, III, and IV. ATP is generated by the influx of these protons back into the mitochondrial matrix through complex V (ATP synthase).

\section{Oxidative Stress}

Oxidative stress arises when there is an imbalance between the production of reactive species (RS) and antioxidant defenses in favor of the former, resulting in an increase in cellular levels of RS $[19,22]$. RS are molecular entities that include reactive oxygen species (ROS), such as superoxide anion, hydrogen peroxide, and the hydroxyl radical, reactive nitrogen species (RNS), including the radicals nitric oxide and nitrogen oxide, as well as reactive halogen and sulfur species. They possess one or more unpaired electrons, thereby rendering them inherently unstable $[19,20,44]$.

ROS, the most extensively studied of the reactive species, are highly reactive molecules or molecular fragments that are continually produced in all aerobic organisms, mostly as a consequence of aerobic respiration and oxidative 
phosphorylation [45]. The close proximity of mtDNA to the site of ROS production makes it more susceptible to oxidative damage and may explain the high frequency of mtDNA mutations seen in cancer [46].

ROS have physiological roles in a number of cellular processes, including effects on vascular tone and platelet adhesion, and, importantly, on intracellular and intercellular signaling [45] (e.g., $\mathrm{H}_{2} \mathrm{O}_{2}$ is a key intracellular messenger at subtoxic levels in signaling pathways involving epidermal growth factor and PI 3-kinases [47, 48]) and induction of apoptosis and senescence $[49,50]$. As mentioned earlier, the mitochondria are a major source of ROS production $[24,25]$. Specifically, during mitochondrial oxidative metabolism and ATP synthesis, the majority of the oxygen consumed is reduced to water. However, about $1 \%-5 \%$ of molecular oxygen is converted to ROS, primarily superoxide anion, which is formed by an initial one-electron reduction of molecular oxygen $[22,45]$. Superoxide can be dismutated by superoxide dismutase to yield hydrogen peroxide. In the presence of partially reduced metal ions, hydrogen peroxide is converted through Fenton and Haber-Weiss reactions to a hydroxyl radical, which is highly reactive and can interact with nucleic acids, lipids, and proteins [44]. Other endogenous sources of ROS production include neutrophils, eosinophils, macrophages, and peroxisomes. ROS can be produced not only as a result of endogenous cellular processes, but also in response to exogenous exposures. Exogenous sources of ROS production include chlorinated compounds, radiation, metal ions, some peroxisome proliferating compounds, hormone therapy, cigarette smoke, and ethanol $[22,51]$.

Antioxidant defenses operate through cellular, membrane, and extracellular mechanisms [44]. Cellular mechanisms include the dismutase, peroxidase, and catalase enzymes; additionally, intracellular ROS production is decreased by the ability of mitochondrial cytochrome oxidase to function catalytically in the electron transport chain without releasing ROS [52]. Cell membrane defenses include antioxidants such as vitamin E, beta-carotene, and coenzyme Q; furthermore, membrane structure is important, in that resistance to antioxidant attack is enhanced by having appropriate proportions of cholesterol and phospholipids. Extracellular antioxidant defenses include the metal-binding proteins (e.g., transferrin), low molecular weight molecules such as bilirubin and vitamin $\mathrm{C}$, and extracellular forms of glutathione peroxidases and superoxide dismutases [44].

\section{Oxidative Stress and Cancer}

There is now substantial evidence to suggest that relative increases in reactive species in the cell, either as a result of physiological modification or through exogenous exposures, contribute to carcinogenesis $[19,22,45]$. There are a number of possible mechanisms through which this might occur. As mentioned earlier, RS can directly damage DNA. For example, the hydroxyl radical may activate oncogenes or inactivate tumor suppressor genes through point mutations, activate chemical carcinogens, and prevent DNA repair [45]. RS might also stimulate the expansion of initiated cell clones through modulation of genes related to apoptosis or proliferation, with resultant stimulation of cell proliferation and suppression of apoptosis $[19,45]$. In addition, the effects of RS may be influenced by polymorphisms in genes involved in carcinogen metabolism, antioxidant defenses, and DNA repair [35].

\section{Oxidative Stress and Breast Cancer}

Several lines of evidence provide support for a role of oxidative stress in the etiology of breast cancer [18]. Markers of oxidative damage, such as DNA adducts and lipid peroxidation products (e.g., DNA-malondialdehyde (MDA) adducts, 8-oxo-7,8-dihydro-2' -deoxyguanosine (8-oxodG)), can be detected in breast tissue, and several relatively small clinical studies have mostly shown that levels of such markers are higher in breast cancer tissue [53-57] and in adjacent normal tissue from breast cancer cases $[55,58,59]$ than in breast tissue from those without breast cancer, although two studies have shown the reverse $[60,61]$. In crosssectional studies, higher levels of oxidative damage markers have also been observed in the serum/plasma [62-69] and urine [70] of breast cancer cases than those of controls, albeit not consistently $[71,72]$. In the only cohort study to date, urinary $15-\mathrm{F}_{2 \mathrm{t}}$-IsoP and $15-\mathrm{F}_{2 \mathrm{t}}$-IsoPM levels (markers of oxidative stress) were associated with increased risk of postmenopausal breast cancer in women with relatively high BMIs $\left(\geq 25 \mathrm{~kg} / \mathrm{m}^{2}\right)$ [73]. Also, urinary MDA excretion has been observed to be higher in women with relatively high breast density (indicative of increased breast cancer risk [74]) than in those with less dense breast tissue [75]. In contrast, in one study, MDA levels in nipple aspirate fluid were shown not to differ between breast cancer cases and controls, whereas levels of 8-iso- $\mathrm{PGF}_{2 \alpha}$, another marker of oxidative stress, were shown to be lower in cases than in controls [76].

\section{The Mitochondrial Genome}

Mitochondria contain their own genome, mitochondrial DNA (mtDNA), which is transmitted through the female germline [77]. MtDNA is located in the mitochondrial matrix and is present in multiple copies per mitochondrion $[38,77]$. The human mitochondrial genome is a closed, double-stranded DNA molecule of 16,569 bp, which contains 37 genes. Most of the genes are located on the heavy $(\mathrm{H})$ strand, which encodes for two ribosomal RNAs, 14 transfer RNAs (tRNAs), and 12 polypeptides (Figure 2) [38]. The light (L) strand encodes for eight tRNAs and a single polypeptide. The 13 protein products are subunits of the enzyme complexes of the respiratory chain/oxidative phosphorylation system [37]. Mammalian mtDNA does not have introns, and has only a few intergenic sequences. The displacement-loop (D-loop) region is a short, threestranded structure in which a short nucleic acid strand, complementary to the L-strand, displaces the $\mathrm{H}$-strand. The D-loop is the major control site for mtDNA expression, 


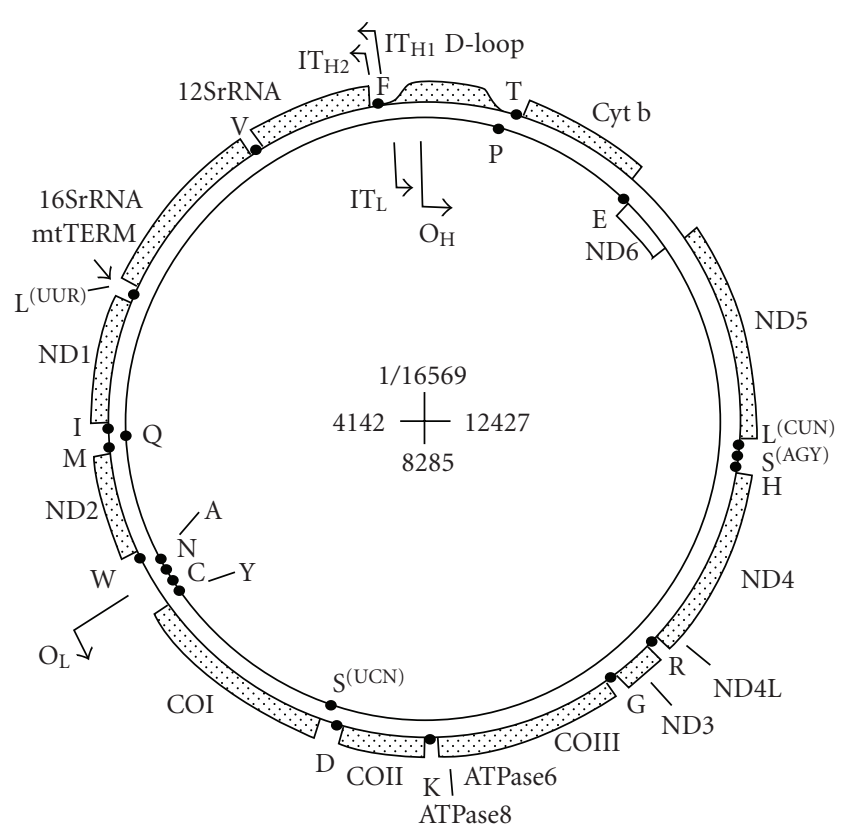

Figure 2: See work by Taanman in [38]. The light (L) strand encodes for eight tRNAs and a single polypeptide. The 13 protein products are subunits of the enzyme complexes of the respiratory chain/oxidative phosphorylation system (DiMauro and Schon, 2003) [37]. Mammalian mtDNA does not have introns, and has only a few intergenic sequences. The displacement loop (D-loop) region is a short, three-stranded structure in which a short nucleic acid strand, complementary to the L-strand, displaces the $\mathrm{H}$ strand. The D-loop is the major control site for mtDNA expression, containing the leading-strand origin of replication and the major promoters for transcription [38].

containing the leading-strand origin of replication and the major promoters for transcription [38].

\section{The Mitochondrial Genome and Cancer}

The mitochondria are not only a major source of ROS production, but, as mentioned earlier, they are also particularly susceptible to damage by ROS because the mitochondrial genome is close to the site of ROS production, lacks histones and introns, and has much less efficient DNA repair mechanisms than nuclear DNA $[24,26,27,46]$. Given the roles of the mitochondria in energy metabolism, generation of reactive oxygen species, aging, and the initiation of apoptosis, mitochondrial damage could contribute to carcinogenesis by causing dysfunctional mitochondrial-induced apoptosis and driving cellular proliferation [78-80].

During cell division, mitochondria segregate randomly among daughter cells [77]. In normal tissues, all copies of mtDNA are identical (homoplasmy). When pathogenic mutations of mtDNA arise, they usually affect some but not all mtDNAs within a cell. Hence, the affected cells (and associated tissues) will contain an admixture of mutant and wild-type mtDNAs, a situation referred to as heteroplasmy. In cancer cells, however, due to clonal expansion most somatic mtDNA mutations appear to be homoplasmic [81].

\section{Alterations in the Mitochondrial Genome and Breast Cancer}

Experimentally, depletion of mtDNA-encoded oxidative phosphorylation genes has been shown to result in tumorigenic transformation of breast epithelial cells [82]. In humans, several studies have shown a relatively high frequency of mtDNA mutations in breast tumor tissue (range 20\%-93\%) [83-88], although the higher estimates may be due partly to sample contamination [87]. Furthermore, a recent study suggested that mtDNA D-loop MnlII site mutations might be associated with increased breast cancer risk [89], and two studies have demonstrated breast cancerspecific deletions in mtDNA $[88,90]$.

In addition to somatic changes, mtDNA variants (polymorphisms) may have subtle effects on ROS production, and it has been postulated that if the variant reduces the efficiency of mitochondrial functioning, the accumulation of ROS may affect cancer risk [91]. Hence, several studies have examined the association between mtDNA variants and breast cancer risk [24, 36, 91-98] (Table 1), but their results do not allow clear conclusions to be drawn regarding specific associations. The G10398A mtDNA polymorphism has received the most attention, and breast cancer risk in association with the $10398 \mathrm{~A}$ allele has been shown to be associated with increased risk in African-Americans [24], Caucasians [91], and East Indians [94] in some studies; not associated with altered risk in either African-Americans [97] or in Caucasians $[95,96]$ in other studies; and associated with decreased risk in one Caucasian (Polish) population (reported as risk in association with A10398G) [93]. The remaining investigations have shown no association with the mtDNA D-loop $(\mathrm{CA})_{n}$ repeat polymorphism in Chinese [98] or with a range of variants in a Spanish population [95]. Bai et al. [91] examined risk in association with 69 mtDNA variants and observed a few that were associated with altered risk. Most studies to date have been relatively small [91, 93-95] and none has undertaken a genome-wide approach, although the study of Bai et al. [91] did focus on variants in the rRNA, mRNA, tRNA, and D-loop regions of mtDNA. Only one study [24] has involved a two-stage approach of first identifying a possible association and then testing it in an independent sample.

It is conceivable that mtDNA variants might act jointly to influence breast cancer risk. Furthermore, several factors involved or potentially involved in the etiology of breast cancer-estrogens, cigarette smoking, alcohol consumption, and caloric intake-might modify mitochondrial function. Investigation of interactions of variants with each other and with environmental exposures is warranted because once patterns of association and interaction are understood, the effects of specific genes and environmental exposures on phenotype may be estimated more accurately [99]. In this regard, two studies have investigated interactions between mtDNA variants and breast cancer risk [36, 92]. In a relatively large study Canter et al. [92] reported a significant interaction between G10398A and T4216C in relation to breast cancer risk in African-American women. In a smaller 
TABLE 1: Association studies of mtDNA variants and breast cancer risk.

\begin{tabular}{|c|c|c|c|c|}
\hline Reference & Study subjects* & Source of study subjects & MtDNA variant (s) & OR $(95 \% \mathrm{CI})^{* *}$ \\
\hline \multirow{3}{*}{$\begin{array}{l}\text { Canter et al. } \\
{[24]}\end{array}$} & 48 AA cases, 54 AA controls (USA) & Hospital-based & G10398A & $2.90(0.61-18.3)$ \\
\hline & $\begin{array}{l}654 \text { AA cases, } 605 \text { AA controls } \\
\text { (USA) }\end{array}$ & \multirow[t]{2}{*}{ Population-based } & \multirow[t]{2}{*}{ G10398A } & $1.60(1.10-2.31)$ \\
\hline & $\begin{array}{l}879 \text { White cases, } 760 \text { White controls } \\
\text { (USA) }\end{array}$ & & & $1.03(0.81-1.31)$ \\
\hline $\begin{array}{l}\text { Canter et al. } \\
{[92]}\end{array}$ & $\begin{array}{l}\text { AA subjects as in Canter et al. } \\
(2005)\end{array}$ & & $\mathrm{T} 4216 \mathrm{C}^{*} \mathrm{G} 10398 \mathrm{~A}$ & $3.31(1.07-10.25)$ \\
\hline $\begin{array}{l}\text { Darvishi et al. } \\
\text { [94] }\end{array}$ & $\begin{array}{l}124 \text { cases, } 273 \text { ethnically matched } \\
\text { controls (India) }\end{array}$ & Details not provided & G10398A & $1.73(1.13-2.66)$ \\
\hline \multirow[t]{9}{*}{ Bai et al. [91] } & \multirow{9}{*}{$\begin{array}{l}156 \text { non-Jewish } \\
\text { European-American cases, } 260 \\
\text { non-Jewish European-American } \\
\text { controls (USA) }\end{array}$} & \multirow{9}{*}{$\begin{array}{l}\text { Cases referred to } \\
\text { Molecular Genetics } \\
\text { Laboratory for BRCA1/2 } \\
\text { testing; controls were } \\
\text { individuals referred for } \\
\text { genetic testing }\end{array}$} & \multicolumn{2}{|l|}{69 variants tested. } \\
\hline & & & \multicolumn{2}{|l|}{ Significant results: } \\
\hline & & & G9055A & $3.03(1.63-5.63)$ \\
\hline & & & A10398G & $1.79(1.14-2.81)$ \\
\hline & & & T16519C & $1.98(1.25-3.12)$ \\
\hline & & & T3197C & $0.31(0.13-0.75)$ \\
\hline & & & G13708A & $0.47(0.24-0.92)$ \\
\hline & & & Haplotype K & $3.30(1.63-5.63)$ \\
\hline & & & Haplotype U & $0.37(0.19-0.73)$ \\
\hline $\begin{array}{l}\text { Mosquera- } \\
\text { Miguel et al. } \\
{[95]}\end{array}$ & $\begin{array}{l}464 \text { cases, } 453 \text { ethnicity-matched } \\
\text { controls (continental Spain), } 302 \\
\text { cases, } 295 \text { ethnicity-matched } \\
\text { controls (Canary Islands) }\end{array}$ & Details not provided & 25 variants tested & $\begin{array}{l}\text { None of the variants } \\
\text { was associated with } \\
\text { altered risk in either } \\
\text { study after } \\
\text { adjustment for } \\
\text { multiple testing }\end{array}$ \\
\hline $\begin{array}{l}\text { Covarrubias } \\
\text { et al. [36] }\end{array}$ & Same subjects as in Bai et al. [91] & & $\begin{array}{l}17 \text { variants tested for all } \\
\text { possible } 2 \text {-way } \\
\text { interactions }\end{array}$ & $\begin{array}{l}\text { A10398G }{ }^{*} \text { A12308G } \\
(P=.004) \\
\text { All other interactions } \\
\text { NS after control for } \\
\text { FWER }\end{array}$ \\
\hline \multirow[t]{3}{*}{$\begin{array}{l}\text { Setiawan et al. } \\
\text { [97] }\end{array}$} & $\begin{array}{l}542 \text { AA cases, } 282 \text { AA controls } \\
\text { (USA) }\end{array}$ & Population-based & G10398A & $1.73(0.87-3.47)$ \\
\hline & $\begin{array}{l}391 \text { AA cases, } 460 \text { AA controls } \\
\text { (USA) }\end{array}$ & Multiethnic cohort & G10398A & $1.08(0.62-1.86)$ \\
\hline & $\begin{array}{l}524 \text { AA cases, } 236 \text { AA controls } \\
\text { (USA) }\end{array}$ & Population-based & G10398A & $0.81(0.43-1.51)$ \\
\hline \multirow[t]{6}{*}{ Ye et al. [98] } & \multirow[t]{6}{*}{$\begin{array}{l}1058 \text { Chinese cases, } 1129 \text { Chinese } \\
\text { controls (China) }\end{array}$} & \multirow[t]{6}{*}{ Population-based } & $\begin{array}{l}\text { D-loop }(\mathrm{CA})_{n} \text { repeat } \\
\text { polymorphism: }\end{array}$ & \\
\hline & & & $(\mathrm{CA})_{5}$ & 1.00 (reference) \\
\hline & & & $(\mathrm{CA})_{4}$ & $1.02(0.85-1.21)$ \\
\hline & & & $(\mathrm{CA})_{6}$ & $0.84(0.50-1.41)$ \\
\hline & & & $(\mathrm{CA})_{7}$ & $0.50(0.27-0.93)$ \\
\hline & & & $(\mathrm{CA})_{8-11}$ & $1.59(0.64-3.91)$ \\
\hline $\begin{array}{l}\text { Czarnecka et al. } \\
{[93]}\end{array}$ & $\begin{array}{l}44 \text { Polish cases, } 100 \text { Polish controls } \\
\text { (Poland) }\end{array}$ & $\begin{array}{l}\text { Clinic-based cases, } \\
\text { population-based } \\
\text { controls }\end{array}$ & A10398G & $9.51(2.64-33.88)$ \\
\hline \multirow{3}{*}{$\begin{array}{l}\text { Pezzotti et al. } \\
{[96]}\end{array}$} & \multirow{3}{*}{$\begin{array}{l}1561 \text { cases, } 2209 \text { controls in Nurses' } \\
\text { Health Study; } 678 \text { cases, } 669 \\
\text { controls in Women's Health Study }\end{array}$} & \multirow[t]{3}{*}{ Population-based } & A10398G & \\
\hline & & & Nurses' Health Study & $1.01(0.85-1.19)$ \\
\hline & & & Women's Health Study & $0.94(0.72-1.22)$ \\
\hline
\end{tabular}

${ }^{*}$ AA = African-American; NS = not significant; FWER = familywise error rate

** Canter et al. [24] estimates are crude estimates_adjustment for other factors in population-based component did not change them; Darvishi et al. [94] estimates are crude; Bai et al. [91] $P$-values adjusted for familywise error rate. 


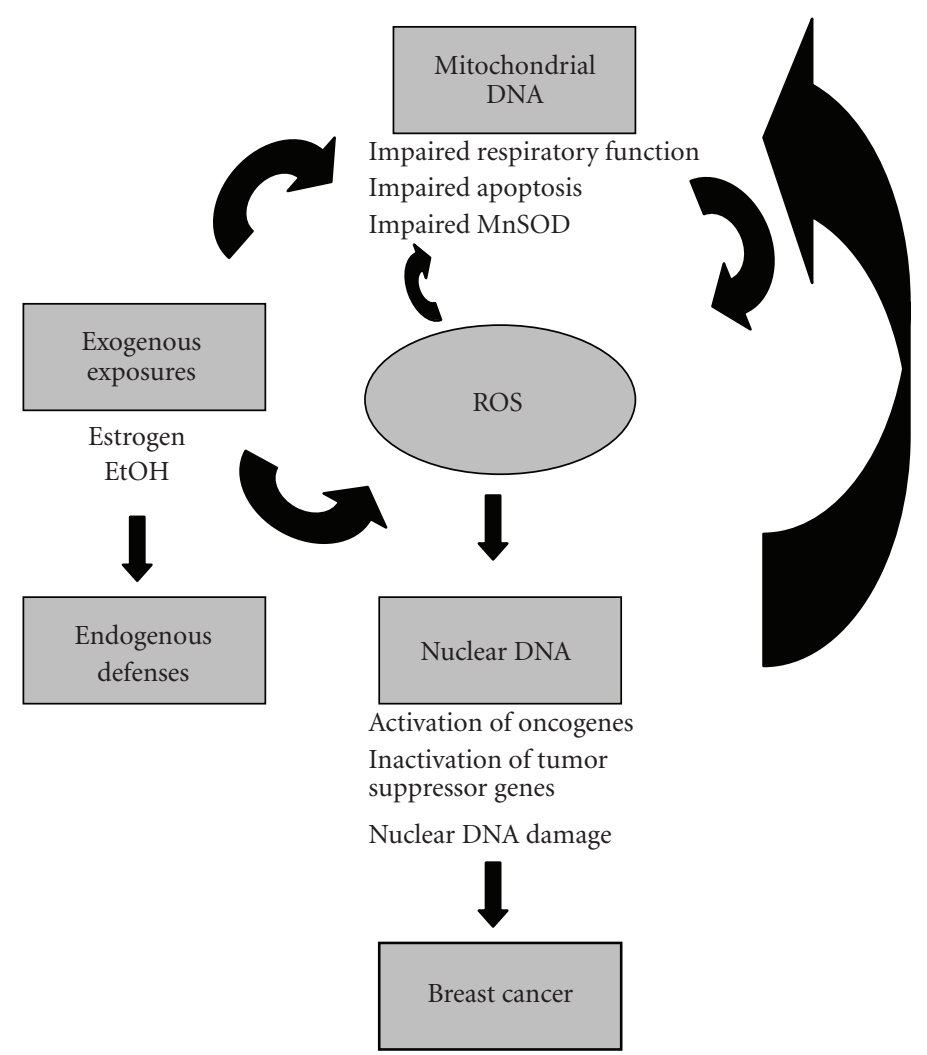

FIgURE 3: Schema showing how ROS may affect mitochondrial and nuclear DNA leading to breast carcinogenesis.

study, Covarrubias et al. [36] evaluated associations between breast cancer risk and two-way interactions between 17 mtDNA variants. One interaction, between variants $12308 \mathrm{G}$ and $10398 \mathrm{G}$, was highly statistically significant, suggesting that these variants increase a woman's risk of breast cancer by a factor of 3 .

In relation to exogenous exposures, susceptibility to the effects of mitochondrial dysfunction may be particularly important in estrogen-related cancers such as breast cancer, because the normal metabolism of estradiol through redoxcycling intermediates may also generate local ROS and oxidative injury in the breast, thereby predisposing to neoplastic transformation [24]. Furthermore, mitochondrial transcription is enhanced by estrogen treatment, suggesting that estrogen-induced mitochondrial transcription is likely to contribute to breast carcinogenesis [51, 100]. Smokingrelated damage to respiratory chain function in lymphocytes has been correlated with measures of oxidative damage [101, 102], and smoking-related oxidative damage has been shown to inhibit mitochondrial enzyme activity in platelets and to cause mitochondrial dysfunction in alveolar macrophages [103]. Two recent studies have shown that cigarette smoking is associated with an increase in mitochondrial DNA copy number $[101,104]$, which might represent a compensatory response to smoking-induced oxidative damage [104]. Shen et al. [105] found that mtDNA copy number had a significant positive association with risk of breast cancer and a significant inverse association with several important endogenous antioxidants (glutathione, CuZnSOD activity, and catalase) and the prooxidant myeloperoxidase, suggesting that mtDNA copy number may be associated with breast cancer risk, possibly through an oxidative stress mechanism.

Alcohol consumption is associated with the generation of ROS [18], and a recent study showed that alcohol consumption was associated with an increase in breast cancer risk only in those with the G allele of the A10398G polymorphism [96]. Another recent study [106] found no difference in the frequency of mtDNA mutations by alcohol intake, dietary intake, or MnSOD genotype [106].

Finally, the mitochondria use oxidative phosphorylation to convert dietary calories into usable energy, and they generate ROS as a toxic by-product. Hence, it has been proposed that interaction between dietary caloric intake at modern levels (in conjunction with a sedentary lifestyle) and mtDNA polymorphisms favorable for selective adaptation to cold Northern climates during human evolution might influence disease risk [79]. In this regard, it is of interest that insulin-resistant individuals have been observed to have defects in mitochondrial content, structure, and function, with possible consequences for mitochondrial energetics [107].

Figure 3 presents a schema for how exogenous exposures, endogenous defences, and mtDNA variants might influence ROS production, subsequent DNA damage, and breast cancer risk. 


\section{Functional Studies of Mitochondrial Changes in Cancer Cells}

The functional significance of germline variants and somatic mtDNA alterations with respect to cancer development is not well understood. However, it is clear that not all mtDNA alterations or germline variants are functionally significant [85, 108-112]. Indeed, the majority of the somatic mtDNA alterations identified so far does not have clear pathogenic roles, and may simply represent the consequences of genomic instability and oxidative DNA damage during the multistep carcinogenic process [110]. However, a small number of alterations may allow a selective growth advantage for tumorigenesis [113] or may initiate cross-talk with the nucleus, thereby altering expression of genes involved in energy metabolism and tumorigenesis [110]. The mtDNA G10398A polymorphism, which results in the substitution of threonine for alanine within the NADH dehydrogenase (ND3) subunit of Complex I and has been associated with increased risk of breast cancer in African-Americans in some studies, may lead to increased ROS production [24]. Although the effect of each individual alteration or variant may be subtle, cumulatively such changes may have functional consequences.

\section{Recommendations for Further Research}

To date, few studies have examined the association of genetic variants or somatic mutations in mitochondrial DNA with the risk of breast cancer. In addition, few studies have investigated risk in association with interactions between specific genetic variants, or with interactions between genetic variants and established breast cancer risk factors (e.g., alcohol consumption and hormone therapy). Below we describe several promising directions for exploring the role of mitochondrial DNA in the development of breast cancer.

\section{Genome-Wide Association Studies}

Disease-associated mutations in high- $(B R C A 1 / 2)$ or moderate-risk (TP53, PTEN, LKB1, CDH1, ATM, RAD50, CHEK2) susceptibility genes identified to date explain only $25 \%$ of the familial aggregation of breast cancers and only a smaller proportion $(\sim 5 \%-10 \%)$ of sporadic disease $[3,114,115]$. Thus it is clear that there must be other candidate genes that contribute modestly to risk [116]. Genome-wide association studies (GWAS) represent one approach to the identification of such genes, and their conduct has been facilitated by the development of the HapMap, a genome-wide database of patterns of human genetic variation [99, 117]. GWAS have the potential not only to facilitate risk prediction but also to provide novel insights into disease mechanisms [99]. However, the HapMap focuses on nuclear DNA, and, to date, there have been no genome-wide association studies of mtDNA and breast cancer risk. However, such studies are warranted in light of the fact that small-scale studies that have tested a limited number of mtDNA polymorphisms have provided some support for a role for mtDNA variants in influencing breast cancer risk. Given that most associations identified through genome-wide studies do not involve previous candidate genes, the results of genome-wide studies may immediately suggest new biological hypotheses [99] and provide a basis for functional studies. In view of the putative role of oxidative stress in carcinogenesis, and of the mitochondria as a major source of ROS production, such studies have the potential to provide valuable insights into the role of the mitochondria in the etiology of breast cancer.

In order to investigate the pathogenic significance of germline variants and somatic mtDNA alterations, additional functional studies of the effects of alterations in the mitochondrial genome of cancer cells are required.

\section{Interplay between Mitochondrial and Nuclear DNA Variants}

In addition to focusing on the association of polymorphisms in mitochondrial DNA with breast cancer risk, the interplay between mitochondrial DNA variants and nuclear DNA variants also merits examination. For example, the subunits of complex II of the respiratory chain complex are encoded entirely by nuclear genes, and three of these genes have been shown to be tumor suppressors [118]. Furthermore, mitochondrial DNA synthesis, replication, transcription, and translation are under nuclear control [119], and nuclear-mitochondrial communication disorders have been described, which result in a loss of integrity of the mitochondrial genome [118]. Therefore, if genomewide association studies uncover genetic variants associated with breast cancer risk, a next step would be to conduct studies focusing on nuclear DNA (nDNA) variants that encode for mitochondrial proteins, to examine both the association between these variants and breast cancer risk and the interaction between $\mathrm{nDNA}$ and $\mathrm{mtDNA}$ variants in relation to risk.

\section{Conclusion}

To date, most studies examining the role of mitochondrial damage in carcinogenesis have focused on mtDNA somatic mutations. In view of the putative role of oxidative stress in carcinogenesis, and of the mitochondria as a major source of ROS production, the role of mitochondrial DNA variants in the etiology of breast cancer represents a potentially promising area of study. Genome-wide association studies are likely to identify new mtDNA variants which modify breast cancer risk. In addition to assessing the main effects of specific variants, gene-gene and gene-environment interactions are likely to explain a greater proportion of the variability in breast cancer risk. The results of such studies might have translational potential, given that they may provide insight into the biological processes underlying breast cancer development, and, hence, suggest strategies for prevention and therapy [99]. 


\section{References}

[1] P. Lichtenstein, N. V. Holm, P. K. Verkasalo, et al., "Environmental and heritable factors in the causation of cancer: analyses of cohorts of twins from Sweden, Denmark, and Finland," The New England Journal of Medicine, vol. 343, no. 2, pp. 78-85, 2000.

[2] V. Beral, D. Bull, R. Doll, R. Peto, and G. Reeves, "Familial breast cancer: collaborative reanalysis of individual data from 52 epidemiological studies including 58209 women with breast cancer and 101986 women without the disease," The Lancet, vol. 358, no. 9291, pp. 1389-1399, 2001.

[3] D. Thompson and D. Easton, "The genetic epidemiology of breast cancer genes," Journal of Mammary Gland Biology and Neoplasia, vol. 9, no. 3, pp. 221-236, 2004.

[4] L. C. Hartmann, T. A. Sellers, M. H. Frost, et al., "Benign breast disease and the risk of breast cancer," The New England Journal of Medicine, vol. 353, no. 3, pp. 229-237, 2005.

[5] S. J. Schnitt, "Benign breast disease and breast cancer risk: morphology and beyond," American Journal of Surgical Pathology, vol. 27, no. 6, pp. 836-841, 2003.

[6] H. Adami, D. Hunter, and D. Trichopoulous, Eds., Textbook of Cancer Epidemiology, Oxford University Press, New York, NY, USA, 2002.

[7] J. L. Kelsey, M. D. Gammon, and E. M. John, "Reproductive factors and breast cancer," Epidemiologic Reviews, vol. 15, no. 1, pp. 36-47, 1993.

[8] J. Russo, R. Moral, G. A. Balogh, D. Mailo, and I. H. Russo, "The protective role of pregnancy in breast cancer," Breast Cancer Research, vol. 7, no. 3, pp. 131-142, 2005.

[9] V. Beral, "Breast cancer and hormone replacement therapy: collaborative reanalysis of data from 51 epidemiological studies of 52,705 women with breast cancer and 108,411 women without breast cancer," The Lancet, vol. 350, no. 9084, pp. 1047-1059, 1997.

[10] J. E. Rossouw, G. L. Anderson, R. L. Prentice, et al., "Risks and benefits of estrogen plus progestin in healthy postmenopausal women: principal results from the women's health initiative randomized controlled trial," Journal of the American Medical Association, vol. 288, no. 3, pp. 321-333, 2002.

[11] E. Linos, M. D. Holmes, and W. C. Willett, "Diet and breast cancer," Current Oncology Reports, vol. 9, no. 1, pp. 31-41, 2007.

[12] N. Hamajima, K. Hirose, K. Tajima, et al., "Alcohol, tobacco and breast cancer-collaborative reanalysis of individual data from 53 epidemiological studies, including 58,515 women with breast cancer and 95,067 women without the disease," British Journal of Cancer, vol. 87, no. 11, pp. 1234-1245, 2002.

[13] P. Reynolds, S. Hurley, D. E. Goldberg, et al., "Active smoking household passive smoking, and breast cancer: evidence from the California Teachers Study," Journal of the National Cancer Institute, vol. 96, no. 1, pp. 29-37, 2004.

[14] E. M. Monninkhof, S. G. Elias, F. A. Vlems, et al., "Physical activity and breast cancer: a systematic review," Epidemiology, vol. 18, no. 1, pp. 137-157, 2007.

[15] World Cancer Research Fund/American Institute for Cancer Research, Food, Nutrition, Physical Activity, and the Prevention of Cancer: A Global Perspective, AICR, Washington, DC, USA, 2007.

[16] A. M. Duncan, "The role of nutrition in the prevention of breast cancer," AACN Clinical Issues, vol. 15, no. 1, pp. 119135, 2004.
[17] C. H. Van Gils, P. H. M. Peeters, H. B. Bueno-de-Mesquita, et al., "Consumption of vegetables and fruits and risk of breast cancer," Journal of the American Medical Association, vol. 293, no. 2, pp. 183-193, 2005.

[18] C. B. Ambrosone, "Oxidants and antioxidants in breast cancer," Antioxidants and Redox Signaling, vol. 2, no. 4, pp. 903-917, 2000.

[19] B. Halliwell, "Oxidative stress and cancer: have we moved forward?” Biochemical Journal, vol. 401, no. 1, pp. 1-11, 2007.

[20] D. H. Kang, "Oxidative stress, DNA damage, and breast cancer," AACN Clinical Issues, vol. 13, no. 4, pp. 540-549, 2002.

[21] L. J. Marnett, "Oxyradicals and DNA damage," Carcinogenesis, vol. 21, no. 3, pp. 361-370, 2000.

[22] J. E. Klaunig and L. M. Kamendulis, "The role of oxidative stress in carcinogenesis," Annual Review of Pharmacology and Toxicology, vol. 44, pp. 239-267, 2004.

[23] M. Goodman, R. M. Bostick, C. Dash, W. D. Flanders, and J. S. Mandel, "Hypothesis: oxidative stress score as a combined measure of pro-oxidant and antioxidant exposures," Annals of Epidemiology, vol. 17, no. 5, pp. 394-399, 2007.

[24] J. A. Canter, A. R. Kallianpur, F. F. Parl, and R. C. Millikan, "Mitochondrial DNA G10398A polymorphism and invasive breast cancer in African-American women," Cancer Research, vol. 65, no. 17, pp. 8028-8033, 2005.

[25] J. P. Jakupciak, W. Wang, M. E. Markowitz, et al., "Mitochondrial DNA as a cancer biomarker," Journal of Molecular Diagnostics, vol. 7, no. 2, pp. 258-267, 2005.

[26] M. S. Fliss, H. Usadel, O. L. Caballero, et al., "Facile detection of mitochondrial DNA mutations in tumors and bodily fluids," Science, vol. 287, no. 5460, pp. 2017-2019, 2000.

[27] C. Frezza and E. Gottlieb, "Mitochondria in cancer: not just innocent bystanders," Seminars in Cancer Biology, vol. 19, no. 1, pp. 4-11, 2009.

[28] D. A. Hood, P. J. Adhihetty, M. Colavecchia, et al., "Mitochondrial biogenesis and the role of the protein import pathway," Medicine and Science in Sports and Exercise, vol. 35, no. 1, pp. 86-94, 2003.

[29] M. J. Jackson, S. Papa, J. Bolanos, et al., "Antioxidants, reactive oxygen and nitrogen species, gene induction and mitochondrial function," Molecular Aspects of Medicine, vol. 23, no. 1-3, pp. 209-285, 2002.

[30] J. A. Petros, A. K. Baumann, E. Ruiz-Pesini, et al., "mtDNA mutations increase tumorigenicity in prostate cancer," Proceedings of the National Academy of Sciences of the United States of America, vol. 102, no. 3, pp. 719-724, 2005.

[31] J. D. Yager and J. G. Liehr, "Molecular mechanisms of estrogen carcinogenesis," Annual Review of Pharmacology and Toxicology, vol. 36, pp. 203-232, 1996.

[32] R. M. Wright, J. L. McManaman, and J. E. Repine, "Alcoholinduced breast cancer: a proposed mechanism," Free Radical Biology and Medicine, vol. 26, no. 3-4, pp. 348-354, 1999.

[33] M. Brandon, P. Baldi, and D. C. Wallace, "Mitochondrial mutations in cancer," Oncogene, vol. 25, no. 34, pp. 46474662, 2006.

[34] J. S. Carew and P. Huang, "Mitochondrial defects in cancer," Molecular Cancer, vol. 1, article 9, 2002.

[35] J. E. Klaunig, L. M. Kamendulis, and B. A. Hocevar, "Oxidative stress and oxidative damage in carcinogenesis," Toxicologic Pathology, vol. 38, no. 1, pp. 96-109, 2010.

[36] D. Covarrubias, R.-K. Bai, L.-J. C. Wong, and S. M. Leal, "Mitochondrial DNA variant interactions modify breast cancer risk," Journal of Human Genetics, vol. 53, no. 10, pp. 924-928, 2008. 
[37] S. DiMauro and E. A. Schon, "Mitochondrial respiratorychain diseases," The New England Journal of Medicine, vol. 348, no. 26, pp. 2656-2668, 2003.

[38] J.-W. Taanman, "The mitochondrial genome: structure, transcription, translation and replication," Biochimica et Biophysica Acta, vol. 1410, no. 2, pp. 103-123, 1999.

[39] S.-Y. Jeong and D.-W. Seol, "The role of mitochondria in apoptosis," Journal of Biochemistry and Molecular Biology, vol. 41, no. 1, pp. 11-22, 2008.

[40] K. Henze and W. Martin, "Evolutionary biology: essence of mitochondria," Nature, vol. 426, no. 6963, pp. 127-128, 2003.

[41] R. Freitas Jr., Basic Capabilities, Landes Bioscience, Austin, Tex, USA, 1999.

[42] A. Vander, J. Sherman, and D. Luciano, Human Physiology: The Mechanisms of Body Function, McGraw-Hill, New York, NY, USA, 5th edition, 1990.

[43] W. Becker and D. Deamer, The World of the Cell, Benjamin/Cummings, Redwood City, Calif, USA, 2nd edition, 1991.

[44] D. J. Betteridge, "What is oxidative stress?" Metabolism, vol. 49 , no. 2, supplement 1, pp. 3-8, 2000.

[45] P. Karihtala and Y. Soini, "Reactive oxygen species and antioxidant mechanisms in human tissues and their relation to malignancies," APMIS, vol. 115, no. 2, pp. 81-103, 2007.

[46] A. Chatterjee, E. Mambo, and D. Sidransky, "Mitochondrial DNA mutations in human cancer," Oncogene, vol. 25, no. 34, pp. 4663-4674, 2006.

[47] Y. S. Bae, S. W. Kang, M. S. Seo, et al., "Epidermal growth factor (EGF)-induced generation of hydrogen peroxide. Role in EGF receptor-mediated tyrosine phosphorylation," Journal of Biological Chemistry, vol. 272, no. 1, pp. 217-221, 1997.

[48] N. R. Leslie, "The redox regulation of PI 3-kinase-dependent signaling," Antioxidants and Redox Signaling, vol. 8, no. 9-10, pp. 1765-1774, 2006.

[49] S. Basu, "F2-isoprostanes in human health and diseases: from molecular mechanisms to clinical implications," Antioxidants and Redox Signaling, vol. 10, no. 8, pp. 1405-1434, 2008.

[50] S. Nemoto and T. Finkel, "Ageing and the mystery at Arles," Nature, vol. 429, no. 6988, pp. 149-152, 2004

[51] J. Q. Chen, T. R. Brown, and J. D. Yager, "Mechanisms of hormone carcinogenesis: evolution of views, role of mitochondria," Advances in Experimental Medicine and Biology, vol. 630, pp. 1-18, 2008.

[52] B. Chance, H. Sies, and A. Boveris, "Hydroperoxide metabolism in mammalian organs," Physiological Reviews, vol. 59, no. 3, pp. 527-605, 1979.

[53] R. Kumaraguruparan, J. Kabalimoorthy, and S. Nagini, "Correlation of tissue lipid peroxidation and antioxidants with clinical stage and menopausal status in patients with adenocarcinoma of the breast," Clinical Biochemistry, vol. 38, no. 2, pp. 154-158, 2005.

[54] D. C. Malins and R. Haimanot, "Major alterations in the nucleotide structure of DNA in cancer of the female breast," Cancer Research, vol. 51, no. 19, pp. 5430-5432, 1991.

[55] D. C. Malins, E. H. Holmes, N. L. Polissar, and S. J. Gunselman, "The etiology of breast cancer: characteristic alterations in hydroxyl radical-induced DNA base lesions during oncogenesis with potential for evaluating incidence risk," Cancer, vol. 71, no. 10, pp. 3036-3043, 1993.

[56] J. Musarrat, J. Arezina-Wilson, and A. A. Wani, "Prognostic and aetiological relevance of 8-hydroxyguanosine in human breast carcinogenesis," European Journal of Cancer, vol. 32, no. 7, pp. 1209-1214, 1996.
[57] F. Tas, H. Hansel, A. Belce, et al., "Oxidative stress in breast cancer," Medical Oncology, vol. 22, no. 1, pp. 11-15, 2005.

[58] D. Li, W. Zhang, J. Zhu, et al., "Oxidative DNA damage and 8hydroxy-2-deoxyguanosine DNA glycosylase/apurinic lyase in human breast cancer," Molecular Carcinogenesis, vol. 31, no. 4, pp. 214-223, 2001.

[59] M. Wang, K. Dhingra, W. N. Hittelman, J. G. Liehr, M. De Andrade, and D. Li, "Lipid peroxidation-induced putative malondialdehyde-DNA adducts in human breast tissues," Cancer Epidemiology Biomarkers and Prevention, vol. 5, no. 9, pp. 705-710, 1996.

[60] A. Gönenç, D. Erten, S. Aslan, M. Akinci, B. Şimşek, and M. Torun, "Lipid peroxidation and antioxidant status in blood and tissue of malignant breast tumor and benign breast disease," Cell Biology International, vol. 30, no. 4, pp. 376380, 2006.

[61] K. Punnonen, M. Ahotupa, K. Asaishi, M. Hyoty, R. Kudo, and R. Punnonen, "Antioxidant enzyme activities and oxidative stress in human breast cancer," Journal of Cancer Research and Clinical Oncology, vol. 120, no. 6, pp. 374-377, 1994.

[62] Z. Djuric, L. K. Heilbrun, M. S. Simon, et al., "Levels of 5-hydroxymethyl-2'-deoxyuridine in DNA from blood as a marker of breast cancer," Cancer, vol. 77, no. 4, pp. 691-696, 1996.

[63] A. Gönenç, Y. Özkan, M. Torun, and B. Şimşek, "Plasma malondialdehyde (MDA) levels in breast and lung cancer patients," Journal of Clinical Pharmacy and Therapeutics, vol. 26, no. 2, pp. 141-144, 2001.

[64] Y.-L. Huang, J.-Y. Sheu, and T.-H. Lin, "Association between oxidative stress and changes of trace elements in patients with breast cancer," Clinical Biochemistry, vol. 32, no. 2, pp. 131136, 1999.

[65] S. S. Khanzode, M. G. Muddeshwar, S. D. Khanzode, and G. N. Dakhale, "Antioxidant enzymes and lipid peroxidation in different stages of breast cancer," Free Radical Research, vol. 38, no. 1, pp. 81-85, 2004.

[66] R. Kumaraguruparan, R. Subapriya, J. Kabalimoorthy, and S. Nagini, "Antioxidant profile in the circulation of patients with fibroadenoma and adenocarcinoma of the breast," Clinical Biochemistry, vol. 35, no. 4, pp. 275-279, 2002.

[67] G. Ray, S. Batra, N. K. Shukla, et al., "Lipid peroxidation, free radical production and antioxidant status in breast cancer," Breast Cancer Research and Treatment, vol. 59, no. 2, pp. 163170, 2000.

[68] D. E. Şener, A. Gönenç, M. Akinci, and M. Torun, "Lipid peroxidation and total antioxidant status in patients with breast cancer," Cell Biochemistry and Function, vol. 25, no. 4, pp. 377-382, 2007.

[69] C.-C. Yeh, M.-F. Hou, S.-M. Tsai, et al., "Superoxide anion radical, lipid peroxides and antioxidant status in the blood of patients with breast cancer," Clinica Chimica Acta, vol. 361, no. 1-2, pp. 104-111, 2005.

[70] P. Rossner Jr., M. D. Gammon, M. B. Terry, et al., "Relationship between urinary 15-F2t-isoprostane and 8oxodeoxyguanosine levels and breast cancer risk," Cancer Epidemiology Biomarkers and Prevention, vol. 15, no. 4, pp. 639-644, 2006.

[71] H. Alagol, E. Erdem, B. Sancak, G. Turkmen, M. Camlibel, and G. Bugdayci, "Nitric oxide biosynthesis and malondialdehyde levels in advanced breast cancer," Australian and New Zealand Journal of Surgery, vol. 69, no. 9, pp. 647-650, 1999. 
[72] M. Gerber, S. Richardson, P. Crastes de Paulet, H. Pujol, and A. Crastes de Paulet, "Relationship between vitamin E and polyunsaturated fatty acids in breast cancer. Nutritional and metabolic aspects," Cancer, vol. 64, no. 11, pp. 2347-2353, 1989.

[73] Q. Dai, Y.-T. Gao, X.-O. Shu, et al., "Oxidative stress, obesity, and breast cancer risk: results from the Shanghai Wmen's Health Study," Journal of Clinical Oncology, vol. 27, no. 15, pp. 2482-2488, 2009.

[74] L. J. Martin and N. F. Boyd, "Mammographic density. Potential mechanisms of breast cancer risk associated with mammographic density: hypotheses based on epidemiological evidence," Breast Cancer Research, vol. 10, no. 1, p. 201, 2008.

[75] N. F. Boyd and V. McGuire, "The possible role of lipid peroxidation in breast cancer risk," Free Radical Biology and Medicine, vol. 10, no. 3-4, pp. 185-190, 1991.

[76] F. Mannello, G. A. M. Tonti, S. Pagliarani, et al., "The 8epimer of prostaglandin $\mathrm{F}_{2 \alpha}$, a marker of lipid peroxidation and oxidative stress, is decreased in the nipple aspirate fluid of women with breast cancer," International Journal of Cancer, vol. 120, no. 9, pp. 1971-1976, 2007.

[77] S. DiMauro, "Mitochondrial DNA medicine," Bioscience Reports, vol. 27, no. 1-3, pp. 5-9, 2007.

[78] L. R. Cavalli and B. C. Liang, "Mutagenesis, tumorigenicity, and apoptosis: are the mitochondria involved?" Mutation Research, vol. 398, no. 1-2, pp. 19-26, 1998.

[79] D. C. Wallace, "A mitochondrial paradigm of metabolic and degenerative diseases, aging, and cancer: a dawn for evolutionary medicine," Annual Review of Genetics, vol. 39, pp. 359-407, 2005.

[80] N. Zamzami and G. Kroemer, "The mitochondrion in apoptosis: how Pandora's box opens," Nature Reviews Molecular Cell Biology, vol. 2, no. 1, pp. 67-71, 2001.

[81] W. Zhu, W. Qin, P. Bradley, A. Wessel, C. L. Puckett, and E. R. Sauter, "Mitochondrial DNA mutations in breast cancer tissue and in matched nipple aspirate fluid," Carcinogenesis, vol. 26, no. 1, pp. 145-152, 2005.

[82] M. Kulawiec, A. Safina, M. M. Desouki, et al., "Tumorigenic transformation of human breast epithelial cells induced by mitochondrial DNA depletion," Cancer Biology and Therapy, vol. 7, no. 11, pp. 1732-1743, 2008.

[83] M. S. Bianchi, N. O. Bianchi, and G. Bailliet, "Mitochondrial DNA mutations in normal and tumor tissues from breast cancer patients," Cytogenetics and Cell Genetics, vol. 71, no. 1, pp. 99-103, 1995.

[84] P. Parrella, Y. Xiao, M. Fliss, et al., "Detection of mitochondrial DNA mutations in primary breast cancer and fineneedle aspirates," Cancer Research, vol. 61, no. 20, pp. 76237626, 2001.

[85] D.-J. Tan, R.-K. Bai, and L.-J. C. Wong, "Comprehensive scanning of somatic mitochondrial DNA mutations in breast cancer," Cancer Research, vol. 62, no. 4, pp. 972-976, 2002.

[86] L.-M. Tseng, P.-H. Yin, C.-W. Chi, et al., "Mitochondrial DNA mutations and mitochondrial DNA depletion in breast cancer," Genes Chromosomes and Cancer, vol. 45, no. 7, pp. 629-638, 2006.

[87] C.-Y. Wang, H.-W. Wang, Y.-G. Yao, Q.-P. Kong, and Y.P. Zhang, "Somatic mutations of mitochondrial genome in early stage breast cancer," International Journal of Cancer, vol. 121, no. 6, pp. 1253-1256, 2007.
[88] W. Zhu, W. Qin, and E. R. Sauter, "Large-scale mitochondrial DNA deletion mutations and nuclear genome instability in human breast cancer," Cancer Detection and Prevention, vol. 28, no. 2, pp. 119-126, 2004.

[89] C. Ye, X. O. Shu, L. Pierce, et al., "Mutations in the mitochondrial DNA D-loop region and breast cancer risk," Breast Cancer Research and Treatment, vol. 119, no. 2, pp. 431-436, 2010.

[90] M. A. Dani, S. U. Dani, S. P. Lima, et al., "Less DeltamtDNA4977 than normal in various types of tumors suggests that cancer cells are essentially free of this mutation," Genetics and Molecular Research, vol. 3, no. 3, pp. 395-409, 2004.

[91] R.-K. Bai, S. M. Leal, D. Covarrubias, A. Liu, and L.-J. C. Wong, "Mitochondrial genetic background modifies breast cancer risk," Cancer Research, vol. 67, no. 10, pp. 4687-4694, 2007.

[92] J. A. Canter, A. R. Kallianpur, F. F. Parl, and R. C. Millikan, "In response: mitochondrial DNA G10398A polymorphism and invasive breast cancer in African-American women," Cancer Research, vol. 66, no. 3, pp. 1880-1881, 2006.

[93] A. M. Czarnecka, T. Krawczyk, M. Zdrozny, et al., "Mitochondrial NADH-dehydrogenase subunit 3 (ND3) polymorphism (A10398G) and sporadic breast cancer in Poland," Breast Cancer Research and Treatment, vol. 121, no. 2, pp. 511-518, 2010.

[94] K. Darvishi, S. Sharma, A. K. Bhat, E. Rai, and R. N. K. Bamezai, "Mitochondrial DNA G10398A polymorphism imparts maternal Haplogroup $\mathrm{N}$ a risk for breast and esophageal cancer," Cancer Letters, vol. 249, no. 2, pp. 249255, 2007.

[95] A. Mosquera-Miguel, V. Alvarez-Iglesias, A. Carracedo, et al., "Is mitochondrial DNA variation associated with sporadic breast cancer risk?” Cancer Research, vol. 68, no. 2, pp. 623625, 2008.

[96] A. Pezzotti, P. Kraft, S. E. Hankinson, D. J. Hunter, J. Buring, and D. G. Cox, "The mitochondrial A10398G polymorphism, interaction with alcohol consumption, and breast cancer risk," PLoS One, vol. 4, no. 4, article e5356, 2009.

[97] V. W. Setiawan, L.-H. Chu, E. M. John, et al., "Mitochondrial DNA G10398A variant is not associated with breast cancer in African-American women," Cancer Genetics and Cytogenetics, vol. 181, no. 1, pp. 16-19, 2008.

[98] C. Ye, Y.-T. Gao, W. Wen, et al., "Association of mitochondrial DNA displacement loop (CA) $)_{n}$ dinucleotide repeat polymorphism with breast cancer risk and survival among Chinese women," Cancer Epidemiology Biomarkers and Prevention, vol. 17, no. 8, pp. 2117-2122, 2008.

[99] D. Altshuler, M. J. Daly, and E. S. Lander, "Genetic mapping in human disease," Science, vol. 322, no. 5903, pp. 881-888, 2008.

[100] D. Roy, Q. Cai, Q. Felty, and S. Narayan, "Estrogeninduced generation of reactive oxygen and nitrogen species, gene damage, and estrogen-dependent cancers," Journal of Toxicology and Environmental Health Part B, vol. 10, no. 4, pp. 235-257, 2007.

[101] B. G. Masayesva, E. Mambo, R. J. Taylor, et al., "Mitochondrial DNA content increase in response to cigarette smoking," Cancer Epidemiology Biomarkers and Prevention, vol. 15, no. 1, pp. 19-24, 2006. 
[102] O. Miro, J. R. Alonso, D. Jarreta, J. Casademont, A. UrbanoMarquez, and F. Cardellach, "Smoking disturbs mitochondrial respiratory chain function and enhances lipid peroxidation on human circulating lymphocytes," Carcinogenesis, vol. 20, no. 7, pp. 1331-1336, 1999.

[103] P. R. Smith, J. M. Cooper, G. G. Govan, A. H. V. Harding, and A. H. V. Schapira, "Smoking and mitochondrial function: a model for environmental toxins," Quarterly Journal of Medicine, vol. 86, no. 10, pp. 657-660, 1993.

[104] D. Tan, D. S. Goerlitz, R. G. Dumitrescu, et al., "Associations between cigarette smoking and mitochondrial DNA abnormalities in buccal cells," Carcinogenesis, vol. 29, no. 6, pp. 1170-1177, 2008.

[105] J. Shen, M. Platek, A. Mahasneh, C. B. Ambrosone, and H. Zhao, "Mitochondrial copy number and risk of breast cancer: a pilot study," Mitochondrion, vol. 10, no. 1, pp. 62-68, 2010.

[106] M. E. Platek, P. G. Shields, D. Tan, et al., "Alcohol consumption and breast tumor mitochondrial DNA mutations," Breast Cancer Research and Treatment, vol. 121, no. 2, pp. 453-460, 2010.

[107] A. E. Civitarese and E. Ravussin, "Minireview: mitochondrial energetics and insulin resistance," Endocrinology, vol. 149, no. 3, pp. 950-954, 2008.

[108] C. C. Abnet, K. Huppi, A. Carrera, et al., "Control region mutations and 'common deletion' are frequent in the mitochondrial DNA of patients with esophageal squamous cell carcinoma," BMC Cancer, vol. 4, article 30, 2004.

[109] H.-C. Lee, S.-H. Li, J.-C. Lin, C.-C. Wu, D.-C. Yeh, and Y.-H. Wei, "Somatic mutations in the D-loop and decrease in the copy number of mitochondrial DNA in human hepatocellular carcinoma," Mutation Research, vol. 547, no. 1-2, pp. 71-78, 2004.

[110] Y. Ma, R.-K. Bai, R. Trieu, and L.-J. C. Wong, "Mitochondrial dysfunction in human breast cancer cells and their transmitochondrial cybrids," Biochimica et Biophysica Acta, vol. 1797, no. 1, pp. 29-37, 2010.

[111] D.-J. Tan, J. Chang, L.-L. Liu, et al., "Significance of somatic mutations and content alteration of mitochondrial DNA in esophageal cancer," BMC Cancer, vol. 6, article 93, 2006.

[112] P. H. Yin, H. C. Lee, G. Y. Chau, et al., "Alteration of the copy number and deletion of mitochondrial DNA in human hepatocellular carcinoma," British Journal of Cancer, vol. 90, no. 12, pp. 2390-2396, 2004.

[113] K. Polyak, Y. Li, H. Zhu, et al., "Somatic mutations of the mitochondrial genome in human colorectal tumours," Nature Genetics, vol. 20, no. 3, pp. 291-293, 1998.

[114] A. Antoniou, P. D. P. Pharoah, S. Narod, et al., "Average risks of breast and ovarian cancer associated with BRCA1 or BRCA2 mutations detected in case series unselected for family history: a combined analysis of 22 studies," American Journal of Human Genetics, vol. 72, no. 5, pp. 1117-1130, 2003.

[115] A. R. Bradbury and O. I. Olopade, "Genetic susceptibility to breast cancer," Reviews in Endocrine and Metabolic Disorders, vol. 8, no. 3, pp. 255-267, 2007.

[116] A. C. Antoniou and D. F. Easton, "Models of genetic susceptibility to breast cancer," Oncogene, vol. 25, no. 43, pp. 5898-5905, 2006.

[117] T. A. Manolio, L. D. Brooks, and F. S. Collins, "A HapMap harvest of insights into the genetics of common disease," Journal of Clinical Investigation, vol. 118, no. 5, pp. 15901605, 2008.
[118] E. A. Shoubridge, "Nuclear genetic defects of oxidative phosphorylation," Human Molecular Genetics, vol. 10, no. 20, pp. 2277-2284, 2001.

[119] S. Koene and J. Smeitink, "Mitochondrial medicine: entering the era of treatment," Journal of Internal Medicine, vol. 265, no. 2, pp. 193-209, 2009. 


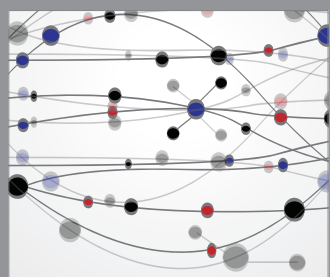

The Scientific World Journal
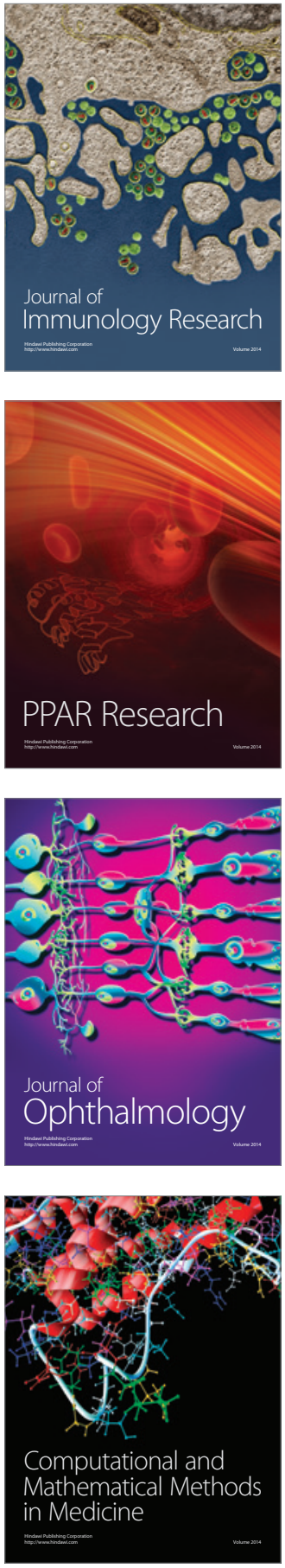

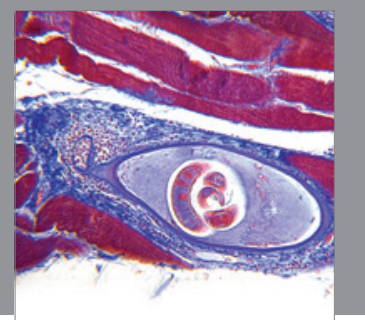

Gastroenterology

Research and Practice
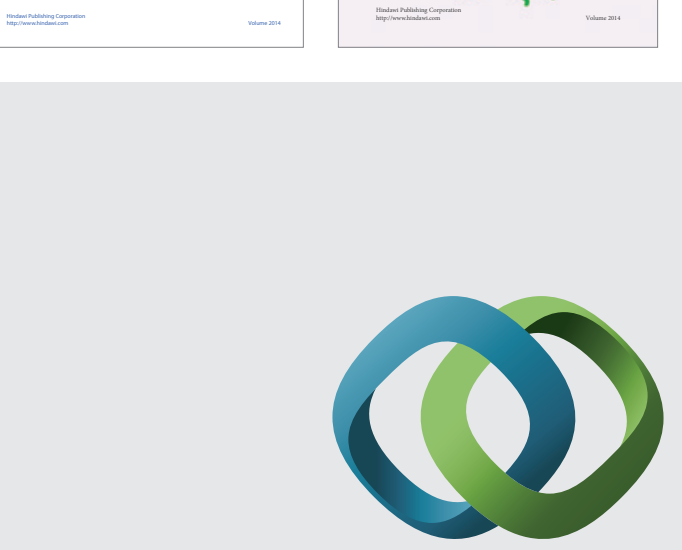

\section{Hindawi}

Submit your manuscripts at

http://www.hindawi.com
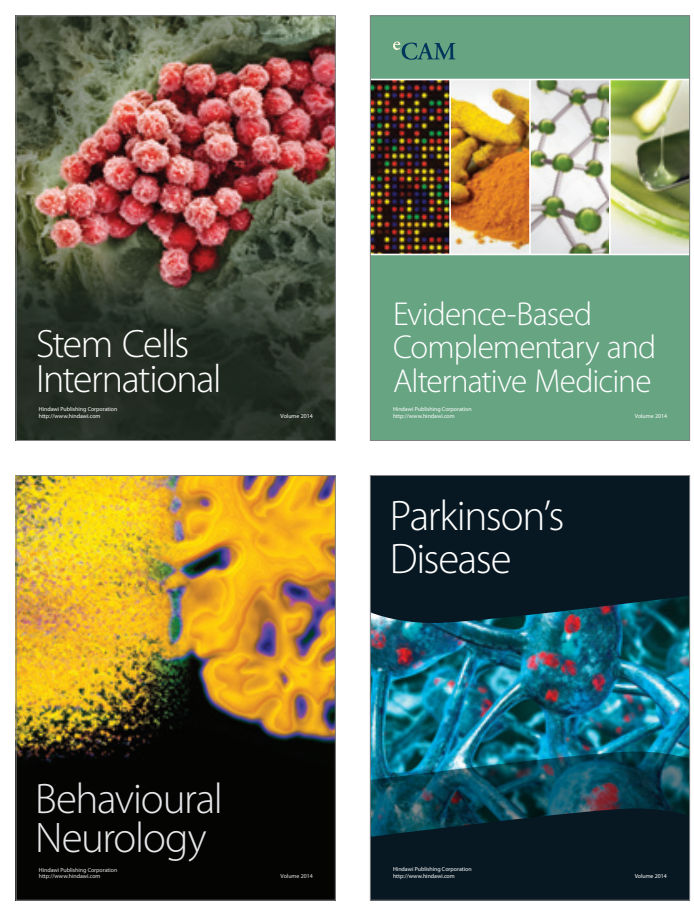

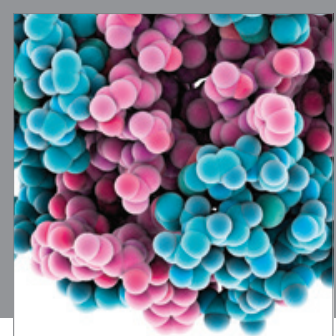

Journal of
Diabetes Research

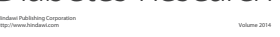

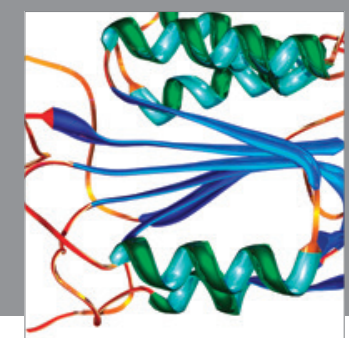

Disease Markers
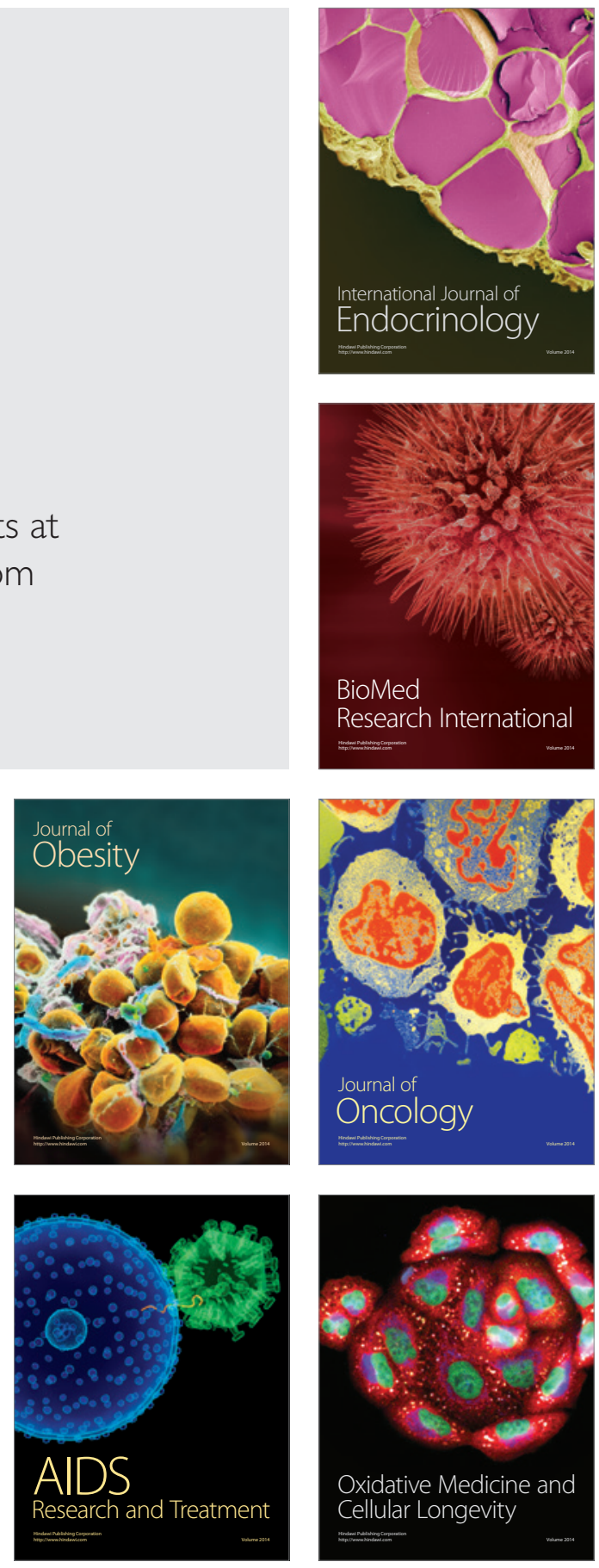